Research Article

\title{
A Stability Indicating HPLC Assay Method for Analysis of Rivastigmine Hydrogen Tartrate in Dual-Ligand Nanoparticle Formulation Matrices and Cell Transport Medium
}

\author{
Naz Hasan Huda (D), Bhawna Gauri (D), Heather A. E. Benson, and Yan Chen (iD \\ School of Pharmacy and Biomedical Sciences, Curtin Health Innovation Research Institute, Curtin University, Perth, \\ WA 6845, Australia \\ Correspondence should be addressed to Yan Chen; y.chen@curtin.edu.au
}

Received 6 September 2017; Accepted 9 January 2018; Published 1 March 2018

Academic Editor: Bengi Uslu

Copyright (C) $2018 \mathrm{Naz}$ Hasan Huda et al. This is an open access article distributed under the Creative Commons Attribution License, which permits unrestricted use, distribution, and reproduction in any medium, provided the original work is properly cited.

\begin{abstract}
The objective of this study was to develop and validate a method for quantitative analysis of rivastigmine hydrogen tartrate (RHT) in dual-ligand polymeric nanoparticle formulation matrices, drug release medium, and cellular transport medium. An isocratic HPLC analysis method using a reverse phase $\mathrm{C}_{18}$ column and a simple mobile phase without buffer was developed, optimised, and fully validated. Analyses were carried out at a flow rate of $1.5 \mathrm{~mL} / \mathrm{min}$ at $50^{\circ} \mathrm{C}$ and monitored at $214 \mathrm{~nm}$. This HPLC method exhibited good linearity, accuracy, and selectivity. The recovery (accuracy) of RHT from all matrices was greater than $99.2 \%$. The RHT peak detected in the samples of a forced degradation study, drug loading study, release study, and cellular transport study was pure and free of matrix interference. The limit of detection (LOD) and limit of quantification (LOQ) of the assay were $60 \mathrm{ng} / \mathrm{mL}$ and $201 \mathrm{ng} / \mathrm{mL}$, respectively. The method was rugged with good intra- and interday precision. This stability indicating HPLC method was selective, accurate, and precise for analysing RHT loading and its stability in nanoparticle formulation, RHT release, and cell transport medium.
\end{abstract}

\section{Introduction}

There is a worldwide increase in the prevalence of brain diseases such as Alzheimer's disease (AD), Parkinson's disease, and stroke due to the increase of the aging population. Consequently, there is an increase in demand for effective treatments for these diseases. Rivastigmine hydrogen tartrate (RHT) was approved by the US FDA in 2000 for the treatment of mild-to-moderate dementia of either Alzheimer's type or related to Parkinson's disease [1]. RHT is a cholinesterase inhibitor that inhibits both acetylcholinesterase (AChE) and butyrylcholinesterase (BuChE) enzymes responsible for the degradation of acetylcholine (ACh) into nonfunctional metabolites. Among the many chemical changes that the brain encounters during $A D$, depletion of ACh is one of the earliest and biggest changes. RHT increases the central cholinergic function by enhancing the $\mathrm{ACh}$ level in mild-to-moderate $\mathrm{AD}$ patients and inhibits deposition of amyloid plaques in the brain, slowing down the mental decline [2-6].

RHT has been reported to improve or maintain patients' cognitive function, global function, behaviour, and day-to-day activities $[7,8]$. It is commercially available as capsules, oral solution, and patches. However, the current therapeutic regimen of RHT demands frequent dosing, and cholinergic side effects are common. Like other CNS drugs, treatment efficacy of RHT is primarily restricted, not by the drug's inherent potency but by its ability to cross the bloodbrain barrier (BBB) into the brain due to its hydrophilic nature [9].

To overcome the challenge of RHT transport into the brain, it has been formulated into nanoparticles (NPs) since 2008 [9]. NPs act as a drug carrier to provide targeted delivery of a concentrated payload to, and sustained release at, the target site for therapeutic action. The targeting ability of NPs is influenced by surface ligands that interact 
TABLE 1: Summary of published HPLC conditions for RHT determinations.

\begin{tabular}{|c|c|c|c|c|c|c|c|}
\hline Column & $\begin{array}{l}\text { Sample } \\
\text { matrix }\end{array}$ & Mobile phase & Flow rate & Detection technique & $\begin{array}{c}\text { Analysis } \\
\text { time }\end{array}$ & $\begin{array}{l}\text { Detection } \\
\text { limits }\end{array}$ & Reference \\
\hline $\begin{array}{l}\text { Waters } \\
\text { Spherisorb } \\
\text { silica }\end{array}$ & $\begin{array}{l}\text { Human } \\
\text { plasma }\end{array}$ & $\begin{array}{l}\text { Acetonitrile- } 50 \mathrm{mM} \\
\text { aqueous sodium } \\
\text { dihydrogen phosphate } \\
(17: 83 \mathrm{v} / \mathrm{v}, \mathrm{pH} 3.1)\end{array}$ & $1.3 \mathrm{~mL} / \mathrm{min}$ & UV: $200 \mathrm{~nm}$ & $\begin{array}{c}6 \\
\text { minutes }\end{array}$ & $\begin{array}{l}\text { LOD: } \\
0.2 \mathrm{ng} / \mathrm{mL} \\
\text { LOQ: } \\
0.5 \mathrm{ng} / \mathrm{mL}\end{array}$ & {$[26]$} \\
\hline $\begin{array}{l}\text { Inertsil } \\
\text { ODS-3V C } 18\end{array}$ & $\begin{array}{l}\text { Rat plasma } \\
\text { and brain }\end{array}$ & $\begin{array}{l}\text { Ammonium acetate buffer } \\
(20 \mathrm{mM}, \mathrm{pH} 4.5) \text { and } \\
\text { acetonitrile } 74: 26(\mathrm{v} / \mathrm{v})\end{array}$ & $1.0 \mathrm{~mL} / \mathrm{min}$ & $\begin{array}{l}\text { Fluorescence detector, } \\
\text { Ex/Em wavelength: } \\
220 / 293 \mathrm{~nm}\end{array}$ & $\begin{array}{l}16 \\
\text { minutes }\end{array}$ & $\begin{array}{l}\text { LOD: not } \\
\text { given } \\
\text { LOQ: } \\
10 \mathrm{ng} / \mathrm{mL}\end{array}$ & {$[16]$} \\
\hline $\begin{array}{l}\text { XTerra } \\
\text { RP18 C } 18\end{array}$ & Raw material & $\begin{array}{l}10 \mathrm{mM} \text { sodium-1-heptane } \\
\text { sulphonate }(\mathrm{pH} 3.0) \text { and } \\
\text { acetonitrile } 72: 28(\mathrm{v} / \mathrm{v})\end{array}$ & $1.0 \mathrm{~mL} / \mathrm{min}$ & $\mathrm{UV}: 217 \mathrm{~nm}$ & $\begin{array}{c}13 \\
\text { minutes }\end{array}$ & $\begin{array}{l}\text { LOD: } \\
100 \mathrm{ng} / \mathrm{mL} \\
\text { LOQ: } \\
300 \mathrm{ng} / \mathrm{mL}\end{array}$ & {$[27]$} \\
\hline Monomeric $\mathrm{C}_{18}$ & Rat plasma & $\begin{array}{c}\text { Acetonitrile and } \\
20 \mathrm{mmol} / \mathrm{L} \text { phosphate } \\
\text { buffer, pH } 3.0(25: 75)\end{array}$ & $1.0 \mathrm{~mL} / \mathrm{min}$ & $\begin{array}{l}\text { Fluorescence detector, } \\
\text { Ex/Em wavelength: } \\
220 / 293 \mathrm{~nm}\end{array}$ & $\begin{array}{l}20 \\
\text { minutes }\end{array}$ & $\begin{array}{l}\text { LOD: not } \\
\text { given } \\
\text { LOQ: } \\
25 \mathrm{ng} / \mathrm{mL}\end{array}$ & {$[28]$} \\
\hline $5 \mathrm{C}_{18}-\mathrm{MS}$ & Capsule & $\begin{array}{l}\text { Methanol and water } \\
\qquad(90: 10)\end{array}$ & $1.0 \mathrm{~mL} / \mathrm{min}$ & $\mathrm{UV}: 217 \mathrm{~nm}$ & $\begin{array}{l}\text { Not } \\
\text { given }\end{array}$ & $\begin{array}{l}\text { LOD: not } \\
\text { given } \\
\text { LOQ: } \\
10.9 \mu \mathrm{g} / \mathrm{mL}\end{array}$ & {$[29]$} \\
\hline Kromasil $\mathrm{C}_{8}$ & Liposomes & $\begin{array}{l}20 \mathrm{mmol} \cdot \mathrm{L}^{-1} \text { phosphate } \\
\text { buffer }(\mathrm{pH} \mathrm{3.0)} \text { and } \\
\text { acetonitrile }(75: 25 \%, \mathrm{v} / \mathrm{v})\end{array}$ & $1.0 \mathrm{~mL} / \mathrm{min}$ & $\mathrm{UV}: 210 \mathrm{~nm}$ & $\begin{array}{l}20 \\
\text { minutes }\end{array}$ & $\begin{array}{l}\text { LOD: not } \\
\text { given } \\
\text { LOQ: } \\
10 \mathrm{ng} / \mathrm{mL}\end{array}$ & [17] \\
\hline $\mathrm{C}_{18}$ & $\begin{array}{c}\text { Solid lipid } \\
\text { nanoparticles }\end{array}$ & 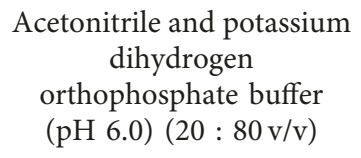 & $1.0 \mathrm{~mL} / \mathrm{min}$ & $\mathrm{UV}: 215 \mathrm{~nm}$ & $\begin{array}{l}\text { Not } \\
\text { given }\end{array}$ & $\begin{array}{l}\text { LOD: not } \\
\text { given } \\
\text { LOQ: } \\
1 \mu \mathrm{g} / \mathrm{mL}\end{array}$ & {$[14]$} \\
\hline ODS $\mathrm{C}_{18}$ & Liposomes & $\begin{array}{c}\text { Acetonitrile : water } \\
\left(20 \mathrm{mM} \mathrm{NaH}_{2} \mathrm{PO}_{4} \cdot 2 \mathrm{H}_{2} \mathrm{O}\right. \\
\left.10 \mathrm{mM} \mathrm{Na} \mathrm{HPO}_{4} \cdot 12 \mathrm{H}_{2} \mathrm{O}\right) \\
(25: 75, \mathrm{v} / \mathrm{v})\end{array}$ & $1.0 \mathrm{~mL} / \mathrm{min}$ & $\mathrm{UV}: 218 \mathrm{~nm}$ & $\begin{array}{l}\text { Not } \\
\text { given }\end{array}$ & $\begin{array}{l}\text { LOD: not } \\
\text { given } \\
\text { LOQ: not } \\
\text { given }\end{array}$ & {$[15]$} \\
\hline
\end{tabular}

specifically at receptors on the target site. This targeting approach is receiving increased attention for the development of highly efficacious therapeutics with minimal side effects that can be used in a wide range of diseases where ideal pharmaceutical options are currently limited. Accurate and efficient analytical methods that can facilitate the formulation development and evaluation process are essential. Our group recently developed dual-targeting ligand NPs for the brain delivery of RHT $[10,11]$. This was facilitated by the development of an analytical method for quantitation of RHT loading in a complex formulation and relevant cellular and stability studies.

In the past, the quantitative determination of RHT has been reported using several analytical techniques such as spectrophotometry [12, 13], HPLC [14-17], gas chromatography-mass spectrometry (GC-MS) [18-20], and liquid chromatography-mass spectrometry (LC-MS) [2125]. For example, Fazil et al. [12] determined drug loading and encapsulation efficiency by measuring the amount of free RHT in the NPs supernatant using a UV spectrophotometer. The group used the same technique to quantify RHT in phosphate-buffered saline (PBS) in their in vitro permeability studies. Nagpal et al. [13] employed spectrophotometry to measure drug loading, entrapment efficiency, and RHT release from NPs in PBS. However, spectrophotometry is not selective and cannot separate formulation excipients, impurities, or degradation products from the drug itself.

HPLC methods developed for RHT commonly employ a buffer in the mobile phase and special columns, such as Kromasil $\mathrm{C}_{8}$, XTerra RP18, and $5 \mathrm{C}_{18}$-MS, with either UV or fluorescence detection for the analysis of RHT in different samples [14-17, 26-29]. Table 1 summarises the HPLC methods reported to date for separation and quantification of RHT in different sample matrices.

Although HPLC coupled with mass spectrophotometry (MS) is suitable or desirable for separation and quantification of RHT in biological samples (rat, canine, and human plasma, and rat brain and urine) [30], for initial formulation development and evaluation, a fast, economic, and simple yet selective and accurate HPLC method is preferred. Furthermore, it is advantageous if the developed method is also directly applicable for HPLC-MS analysis. Therefore, the objective of the current study was to develop and validate a simple, fast, sensitive, selective, and accurate HPLC method for the quantitative analysis of RHT loading in 
a dual-ligand NP formulation, its release and cellular transport, and its stability profile under different stressed conditions. Development criteria were that the chromatography should be achieved on a commonly used $\mathrm{C}_{18}$ column and that the mobile phase was without a buffer, thus allowing direct translation to HPLC-MS.

\section{Experimental}

RHT (purity $\geq 99.2 \%$ ) was purchased from Innochem Technology Co., Ltd. (Beijing, China). HPLC grade acetonitrile (ACN) (purity $\geq 99.9 \%$ ) was obtained from Thermo Fisher Scientific (Scoresby, Australia). Hanks' balanced salt solution (HBSS), 4-2-hydroxyethylpiperazine-1ethanesulfonic acid (HEPES) (purity $\geq 99.5 \%$ ), trifluoroacetic acid (TFA) (purity $\geq 99.0 \%$ ), and phosphate-buffered saline (PBS) pouches were purchased from Sigma-Aldrich (Castle Hill, Australia). D-glucose anhydrous, $\mathrm{HCl}(32 \%$ $\mathrm{w} / \mathrm{v})$, and hydrogen peroxide $\left(\mathrm{H}_{2} \mathrm{O}_{2}, 30 \% \mathrm{w} / \mathrm{v}\right)$ were obtained from Ajax Finechem Pty Ltd. (Taren Point, Australia). $\mathrm{NaOH}$ (purity $\geq 98.0$ ) was obtained from BDH Laboratory Supplies (Poole, England). The transport buffer (HBSS-P) was prepared from HBSS containing $10 \mathrm{mM}$ HEPES and $20 \mathrm{mM}$ glucose. Ultrapure (type 1) water was generated using a Milli-Q System (Merck Millipore, Bayswater, Australia).

2.1. Nanoparticle Preparation and Characterisation. The dual-ligand PLGA-based NPs were prepared by a double emulsion solvent evaporation technique [31-33]. RHT was loaded in the NPs as a model drug. The NPs formulation was optimised to achieve optimum particle size for brain drug delivery and maximal drug loading in the NPs. The optimised NPs formulation was evaluated for in vitro characteristics including particle morphology, size, zeta potential, drug loading efficiency, release profile, and stability studies. The developed HPLC method was used for quantitative analysis of RHT loading in the NPs formulation, release and cellular transport, and stability profile under different stressed conditions.

2.2. Chromatographic Conditions. The HPLC system was an Agilent ${ }^{\circledR} 1200$ instrument (Agilent Technologies, Mulgrave, Australia) with a degasser (G1379B), a binary pump (G1312A), and an autosampler (G1329A) with thermocontrol unit (G1330B) and VWD (G1314B), Waters ${ }^{\circledR}$ 1122/WTC-120 external column heater (Waters Australia Pty Ltd, Rydalmere, Australia), and a diode-array detector (DAD, G1315B). Data acquisition and processing were carried out with Agilent ChemStation ${ }^{\circledR}$ software version B.04.03 SP1.

Samples were maintained at $4^{\circ} \mathrm{C}$ in the autosampler prior to analysis. An Apollo $\mathrm{C}_{18}$ column, $5 \mu \mathrm{m}$ particle size, $150 \mathrm{~mm} \times 4.6 \mathrm{~mm}$ (Grace Davison Discovery Sciences, Baulkham Hills, Australia), was maintained at $50^{\circ} \mathrm{C}$. All analyses were conducted with an isocratic mode with a $1.5 \mathrm{~mL} / \mathrm{min}$ flow rate of the mobile phase $(20 \% \mathrm{v} / \mathrm{v} \mathrm{ACN} \mathrm{in}$ water containing $0.1 \%$ TFA, prefiltered through a $0.2 \mu \mathrm{m}$ hydrophilic nylon filter: Merck Millipore, Bayswater, Australia) and injection volume of $50 \mu \mathrm{L}$. The detection of RHT was monitored at an UV wavelength of $214 \mathrm{~nm}$.

2.3. Forced Degradation Studies. Forced degradation studies were conducted according to published protocols to confirm the selectivity of the developed assay method [34-36]. RHT $(25 \mu \mathrm{g} / \mathrm{mL})$ was used for all degradation studies. For acid decomposition (hydrolysis) studies, RHT solution was prepared in $2 \mathrm{~N} \mathrm{HCl}$ and incubated for $48 \mathrm{~h}$ at $37^{\circ}$ and $60^{\circ} \mathrm{C}$. For base hydrolysis studies, RHT solution was prepared in $0.5 \mathrm{~N} \mathrm{NaOH}$ and incubated at $37^{\circ} \mathrm{C}$ and $60^{\circ} \mathrm{C}$ up to $48 \mathrm{~h}$. Both the acid and alkaline samples were cooled to RT and neutralised before analysis by HPLC.

The stability of RHT in water was assessed with RHT solution $(25 \mu \mathrm{g} / \mathrm{mL})$ incubated at $37^{\circ}$ and $60^{\circ} \mathrm{C}$ for $48 \mathrm{~h}$, whereas the effect of RHT oxidation was determined by incubating RHT for $48 \mathrm{~h}$ at $37^{\circ}$ and $60^{\circ} \mathrm{C}$ in $30 \% \mathrm{H}_{2} \mathrm{O}_{2}$.

All degraded samples were analysed by HPLC, and RHT peak purity was evaluated using a diode-array detector by obtaining five UV spectra across the peak. The similarity among these five spectra was determined and reported using ChemStation software to determine the peak purity. Coelution of any degraded product with the drug peak would make the peak impure, resulting in dissimilar UV spectra. The software also reported whether the peak purity in each spectrum was within the automatically set threshold limit.

2.4. Method Validation. The developed HPLC method was validated with respect to selectivity, linearity, precision, accuracy, limit of detection (LOD), and limit of quantification (LOQ) in accordance with the International Council for Harmonisation (ICH) Guidelines for Validation of Analytical Procedures, Q2B [37] and the United States Pharmacopeia and the National Formulary (USP 37-NF 32) [38].

2.4.1. Selectivity. Forced degradation study samples were used to assess the selectivity of the method. Supernatants of both blank NPs (dual-ligand NPs without any loaded drug) and RHT-loaded dual-ligand NPs were diluted 200 times in the mobile phase and injected into the HPLC to study whether any interfering peaks coeluted at or near the drug peak. Similarly, the matrix interference was also investigated using (i) PBS medium collected from release study control (dual-ligand NPs without any loaded drug) and (ii) uptake/transport study buffer (HBSS-P) comprising HBSS containing $10 \mathrm{mM}$ HEPES and $20 \mathrm{mM}$ glucose (collectively the "experimental media").

2.4.2. Linearity. The linearity of the developed assay method was assessed in two different media: $0.3 \%$ vitamin E-TPGS (solvent for dispersion of dual-ligand nanoparticle) and PBS (release study medium). A range of concentrations of RHT solutions $(0.1$ to $2 \mathrm{mg} / \mathrm{mL}$ ) was prepared in $0.3 \%$ vitamin E-TPGS from a stock solution $(2 \mathrm{mg} / \mathrm{mL}$ RHT in $0.3 \%$ vitamin E-TPGS). Each solution was then diluted 200 times $(50 \mu \mathrm{L}$ into $10 \mathrm{~mL})$ with the mobile phase to obtain the final 
RHT standard concentrations of $0.5,1,2,3,4,5,6,7,8,9$, and $10 \mu \mathrm{g} / \mathrm{mL}$. These standards were injected into the HPLC column, in duplicate. Another set of standards with the same concentration range was prepared by diluting an RHT stock solution $(1 \mathrm{mg} / \mathrm{mL})$ in type 1 water with $10 \mathrm{mM}$ PBS ( $\mathrm{pH} 7.4)$. Again, these standards were injected into the HPLC column in duplicate. Average peak area data were plotted against corresponding standard concentrations using Microsoft $^{\circledR}$ Excel 2016 to construct the standard calibration curve. The linearity was established by calculating the $R^{2}$ value.

2.4.3. Precision. The precision of the proposed method was determined by injecting four RHT concentrations $(1,4,6$, and $10 \mu \mathrm{g} / \mathrm{mL}$ ) in the experimental media, six times into the HPLC. The relative standard deviation (RSD) values were calculated for all concentrations.

2.4.4. Limit of Detection (LOD). The LOD was determined as the drug concentration that produced a signal three times greater than the baseline noise level. Two blank solvents, namely, (1) $0.3 \%$ vitamin E-TPGS diluted 200 times in the mobile phase and (2) $10 \mathrm{mM}$ PBS, pH 7.4, were injected six times to determine the average noise levels. Standard RHT solutions prepared in the mobile phase were analysed and calibration curves constructed by plotting average peak heights against the corresponding concentrations. The LOD was calculated by the following formula:

LOD $=3 \times \frac{\text { Peak height of noise }}{\text { Slope of calibration curve constructed by peak height versus conc }}$.

2.4.5. Limit of Quantification (LOQ). Using the same data, the LOQ was determined as the concentration with the signal at ten times greater than the baseline noise level. The LOQ was calculated by the following formula:

$$
\text { LOQ }=10 \times \frac{\text { Peak height of noise }}{\text { Slope of curve constructed by peak height versus conc }} \text {. }
$$

2.4.6. Intra- and Interday Repeatability (Ruggedness). Three standard concentrations of RHT (low, medium, and high) in each solvent ( $0.3 \%$ vitamin E-TPGS diluted 200 times in the mobile phase and $10 \mathrm{mM}$ PBS, $\mathrm{pH}$ 7.4) within the calibration curve were selected. The intra- and interday repeatability of the method was assessed by analysing these 1,5 , and $10 \mu \mathrm{g} / \mathrm{mL}$ RHT standards, in triplicate, at different time points in the same day and on two different days. In addition, the ruggedness study was conducted by analysing another set of RHT standards of the same concentrations by a second analyst on a different day. The RSD was calculated for each analysed concentration and compared with the nominal limit to evaluate the intra- and interday repeatability of the method and ruggedness.

2.4.7. Accuracy. The accuracy of the developed method was determined in two media to assess the interference of the dual-ligand NPs formulation matrices and solvents. Firstly, a batch of drug-free dual-ligand NPs (blank NPs) was prepared, and the supernatant was collected during the last step of the preparation. The supernatant was then spiked with RHT to obtain a solution of RHT $(2 \mathrm{mg} / \mathrm{mL})$. This stock solution was diluted with the same supernatant medium to prepare five RHT solutions with concentrations of $0.1,0.4$, $0.8,1.2$, and $1.6 \mathrm{mg} / \mathrm{mL}$. These solutions were diluted 200 times with the mobile phase to obtain the final drug concentrations of $0.5,2,4,6,8$, and $10 \mu \mathrm{g} / \mathrm{mL}$ and injected into the HPLC column in triplicate. This procedure mimics the method of sample preparation for the determination of RHT loading in dual-ligand NPs.

Secondly, an in vitro release study of the blank dualligand NPs was carried out at pH 7.4 in PBS (mimicking the NP matrix in the release medium). $3 \mathrm{~mL}$ of blank dual-ligand NPs suspension was loaded in a dialysis tube (MWCO 12000), sealed, and placed in a $60 \mathrm{~g}$ amber glass jar containing $50 \mathrm{~mL}$ prewarmed $\mathrm{PBS}$ at $37^{\circ} \mathrm{C}$. The setup was placed on an orbital shaker at $37^{\circ} \mathrm{C}$ and horizontally shaken at $100 \mathrm{rpm}$. Release medium from outside the dialysis bag was collected after $24 \mathrm{~h}$, spiked with RHT standard solution $(200 \mu \mathrm{g} / \mathrm{mL})$ prepared in type 1 water to get the final RHT concentrations of $2,4,6,8$, and $10 \mu \mathrm{g} / \mathrm{mL}$, and injected into the HPLC column in triplicate. The concentration of RHT in all samples was determined against RHT standards prepared in the mobile phase.

The method accuracy was determined by calculating the percentage of recovery (measured concentration over the added concentration) in each case.

\section{Results and Discussion}

The NP formulation was optimised to achieve the particle size between $70 \mathrm{~nm}$ and $200 \mathrm{~nm}$ as well as to achieve the highest possible drug loading in the NPs. The optimised RHT-loaded dual-ligand NPs were found to have negative zeta potential $(-24.3 \pm 2.5 \mathrm{mV})$ and narrow size distribution $(139.5 \pm 3.9 \mathrm{~nm})$ ideal for targeting the BBB.

3.1. Development and Optimisation of HPLC Method. The HPLC method for separation and quantification of RHT in PBS (pH 7.4) and NP supernatant (containing 0.3\% vitamin E-TPGS) was developed and validated. An appropriate combination of the column type, column temperature, mobile phase composition and flow rate, injection volume, and detection system was studied to produce a simple, fast, economic, and yet selective and accurate assay method. We validated $50 \mu \mathrm{L}$ injection volume as the maximum injection volume for future application in analysis of biological samples. The UV wavelength of $214 \mathrm{~nm}$ was selected for the detection of the compound based on the UV spectrum of RHT. A lower wavelength $(209 \mathrm{~nm})$ produced a much stronger drug signal, but higher background noise made this approach impractical. The mobile phase composition was developed based on the solubility and pKa of RHT (8.85) [39]. An acidic condition ( $\mathrm{pH}$ 2.6) was considered necessary to keep all RHT molecules ionised (Figure 1). At this lower 


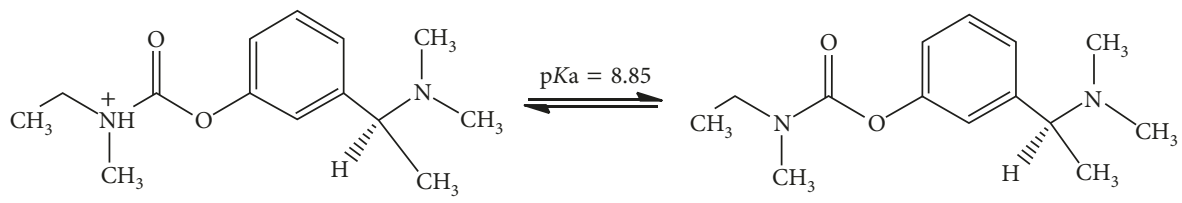

FIGURE 1: Ionisation of rivastigmine tartrate.

TABLE 2: Summary of findings in RHT-forced degradation studies.

\begin{tabular}{|c|c|c|c|}
\hline Forced degradation condition & Temp. $\left({ }^{\circ} \mathrm{C}\right)$ & Incubation duration (hrs) & Remaining percentage \\
\hline \multirow{2}{*}{ Acid hydrolysis: $\mathrm{RHT}$ in $2 \mathrm{~N} \mathrm{HCl}$} & 60 & 48 & 87.4 \\
\hline & 37 & 48 & 97.8 \\
\hline \multirow{3}{*}{ Base hydrolysis: RHT in $0.5 \mathrm{~N} \mathrm{NaOH}$} & 60 & 2 & 80.9 \\
\hline & 60 & 48 & 0.0 \\
\hline & 37 & 48 & 29.7 \\
\hline \multirow{2}{*}{ Hydrolysis: RHT in water } & 60 & 48 & 99.2 \\
\hline & 37 & 48 & 99.7 \\
\hline \multirow{2}{*}{ Oxidation: $\mathrm{RHT}$ in $30 \%(\mathrm{w} / \mathrm{v}) \mathrm{H}_{2} \mathrm{O}_{2}$} & 60 & 48 & 0.0 \\
\hline & 37 & 48 & 79.6 \\
\hline
\end{tabular}

$\mathrm{pH}$, the silane groups of the $\mathrm{C}_{18}$ column were also fully protonated, leading to weak interaction with $\mathrm{RHT}$, thereby shortening the elution time. TFA was used to provide a good peak shape and avoid the use of buffer salts that may precipitate due to an interaction with formulation excipients. In addition, eliminating a buffer allows the method to be easily adapted for LC-MS analysis of RHT in the future. The initial trial mobile phase composed of ACN and water (50:50 v/v) containing $0.1 \%$ TFA at a flow rate of $1 \mathrm{~mL} / \mathrm{min}$ resulted in the RHT eluting with the solvent front. Consequently, the organic phase was optimised at a ratio of $20: 80(\mathrm{v} / \mathrm{v})$ for ACN : water to produce the best peak shape and separation. The flow rate was increased to $1.5 \mathrm{~mL} / \mathrm{min}$, and column temperature was maintained at $50^{\circ} \mathrm{C}$ to facilitate separation, sharpen the peaks, and reduce the retention time to $6.8 \mathrm{~min}$. Mullangi et al. [16] also employed a similar mobile phase composed of ACN and water $(26: 74 \mathrm{v} / \mathrm{v})$ and acidic $\mathrm{pH}$ of 4.5 for the analysis of RHT. However, our developed method utilises a lessexpensive shorter column and a shorter run time, thereby providing economic benefits.

3.2. Forced Degradation of RHTand Selectivity. The main aim of the forced degradation studies of RHT was to assess the selectivity of the analytical method. According to the MSDS supplied by the manufacturer, RHT is chemically stable under normal conditions but incompatible with strong acids, bases, and oxidising agents. No light sensitivity data were provided in the MSDS; however, RHT was reported to be stable when exposed to light for at least ten days [27]. In our investigation, various stress conditions were employed to simulate any possible degradation that might occur during the NPs preparation and in vitro characterisation experiments. RHT was subjected to hydrolysis (acidic, alkaline, and neutral pH) and oxidation. Our results (Table 2) showed a similar degradation pattern for RHT as per the published literature [27]. We found that RHT was most prone to base degradation, showing maximum degradation after $48 \mathrm{~h}$ incubation at $37^{\circ} \mathrm{C}$, compared to acidic, oxidative, and hydrolysis in water conditions. The drug demonstrated excellent stability against hydrolysis conditions at neutral $\mathrm{pH}$ under both test temperatures, but oxidised easily at $37^{\circ} \mathrm{C}$, with complete degradation after $48 \mathrm{~h}$ incubation at $60^{\circ} \mathrm{C}$. RHT stability in $2 \mathrm{~N} \mathrm{HCl}$ was relatively good with $2.2 \%$ degradation at $37^{\circ} \mathrm{C}$ over $48 \mathrm{~h}$.

Figure 2 illustrates that our developed HPLC assay method is capable of separating RHT from all degradation products and that the RHT peak obtained at $6.8 \mathrm{~min}$ is pure. Peak purity analysis was conducted using the default settings of the ChemStation software without any manual data entry. The peak purity of degraded products was not checked because we were only interested in assessing the method's capability of resolving the pure RHT peak. The eluted RHT peak was well separated from the degraded products (retention time $<6 \mathrm{~min}$ ). Thus, the developed method was selective and can be used as a stability indicating method for the analysis of RHT concentration in various samples including stability samples.

As our RHT samples of interest are from dual-ligand nanoparticle formulation, release, and cellular transport studies, it is important that the matrices present in those samples do not interfere with the RHT quantitation. Therefore, further selectivity studies were carried out to confirm that the developed HPLC method has the capability to generate "true results" that are free from matrix or medium interference. The HPLC spectra in Figure 3 indicate that there was no peak around the RHT retention time $(6.8-6.9 \mathrm{~min})$ in any of the experimental media: (i) supernatant of dual-ligand NPs without any loaded drug (after 200 times dilution with the mobile phase), (ii) PBS medium following release study of empty dual-ligand NPs, and (iii) cellular transport study medium (HBSS-P). This 


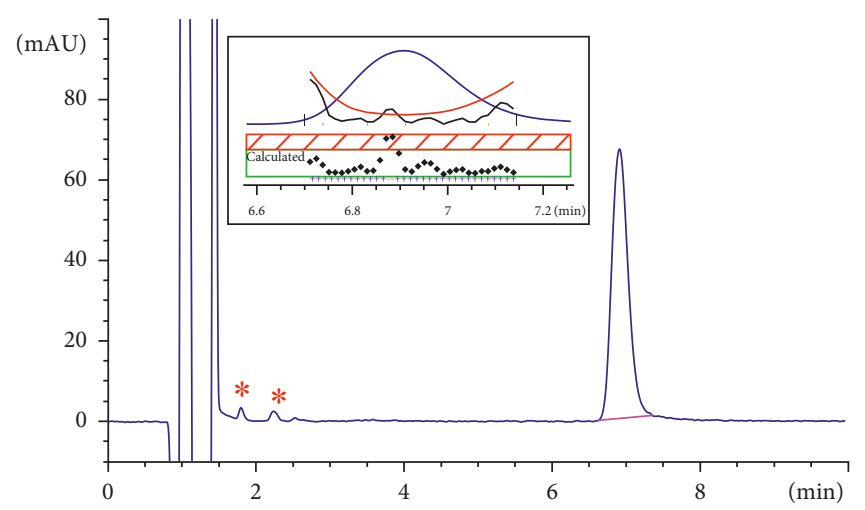

(a)

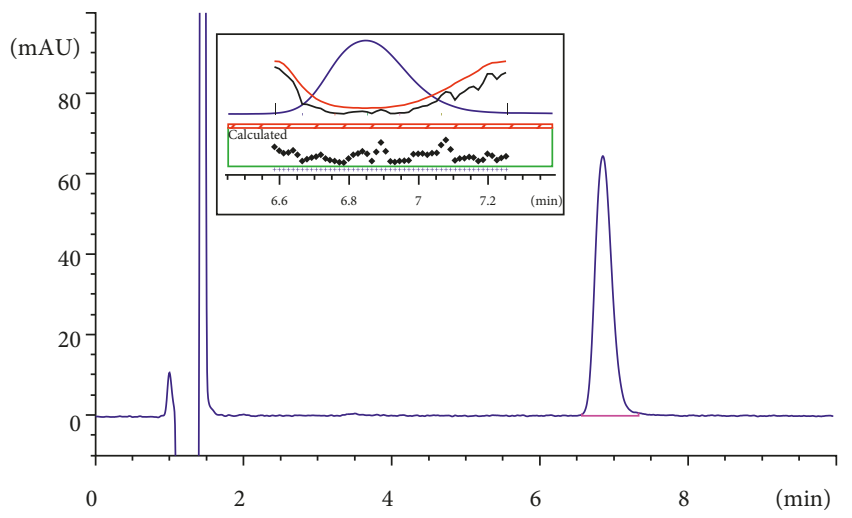

(c)

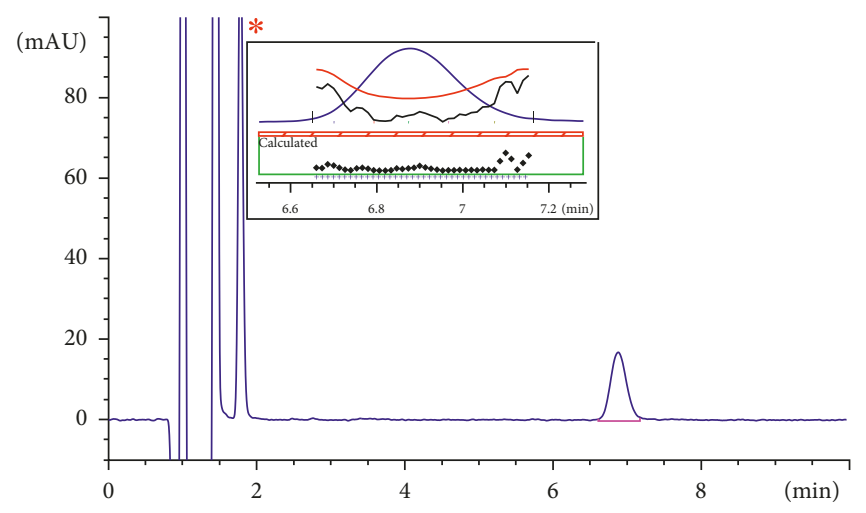

(b)

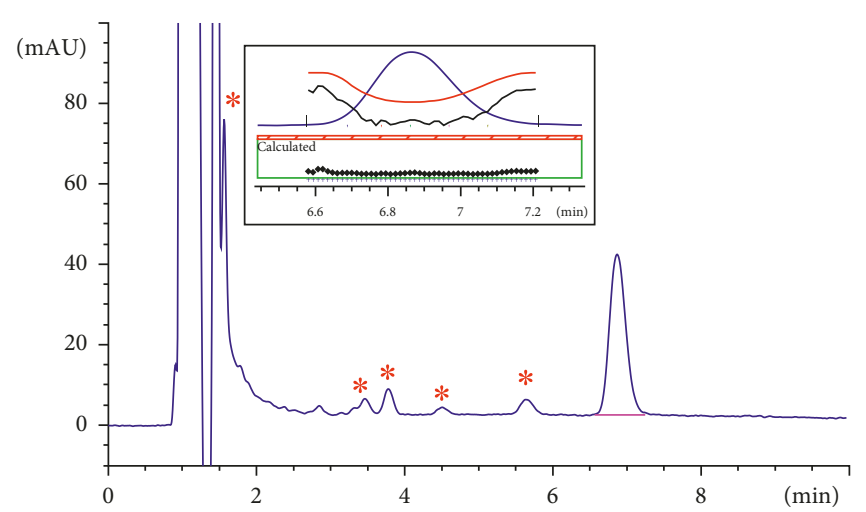

(d)

FiguRE 2: HPLC chromatogram of RHT under various stress conditions conducted at $37^{\circ} \mathrm{C}$ for 48 hours. (a) Acid degradation, (b) alkali degradation, (c) hydrolysis, and (d) oxidation. Analysis of RHT was not interfered by the degradation products (*). Peak purity reports are shown in the insets, confirming that the RHT peaks are pure and the purity factors are within the calculated threshold limit.

demonstrates that there was no matrix interference and the method is selective or specific for analysis of RHT under various conditions.

3.3. Linearity. The detector response to various concentrations of RHT in two media produced a linear relationship. For $50 \mu \mathrm{L}$ injections of RHT in vitamin E-TPGS (following 200 times dilution with the mobile phase), the regression plot demonstrated a nearly perfect linear relationship (coefficient of variance was 0.9999 ) over the concentration range of $0.5-10 \mu \mathrm{g} / \mathrm{mL}$ that covered the concentrations encountered in the RHT loading analysis. The same concentration range of RHT in PBS also demonstrated a good linear relationship with a coefficient of variance of 0.9998 .

3.4. Precision. The precision study was also conducted with the three media used in the selectivity study (Table 3). All RSD values were well below the nominally acceptable level of $\leq 2 \%$ [40]. Even at the low concentrations of RHT $(1 \mu \mathrm{g} / \mathrm{mL})$, the RSD of $1.04-1.28 \%$ was achieved, demonstrating that the method is precise.

3.5. $L O D$ and $L O Q$. The LOD of an analytical procedure is the lowest detectable amount of an analyte in a sample but not necessarily a quantifiable value. For the current method, the lowest detectable concentration of RHT in both solvent systems was $60 \mathrm{ng} / \mathrm{mL}$.

The LOQ is the lowest amount of the drug in the sample that can be confidently quantified using the method. For the current method, the lowest quantifiable concentration of RHT in both solvent systems was $201 \mathrm{ng} / \mathrm{mL}$. The LOD and LOQ is in a comparable range or even better than other published methods [14, 27], and this method can also meet the analytical requirements of dual-ligand NP formulation development and evaluation.

3.6. Intra- and Interday Repeatability. The intra- and interday repeatability data are shown in Table 4. All RSD values of repeated analysis were within the acceptable limit of $\leq 2 \%$ [40]. The ruggedness study performed by different analysts also demonstrated similar trend with RSD values below 2\% (data not shown). These results suggest that the developed method is rugged.

3.7. Accuracy. The accuracy of a method demonstrates that the assay can accurately quantify the molecule(s) of interest in the presence of other possible interfering 


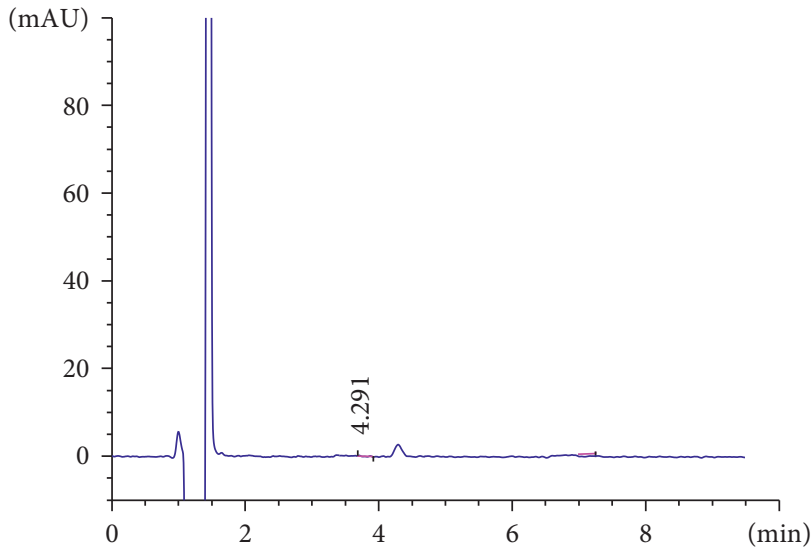

(a)

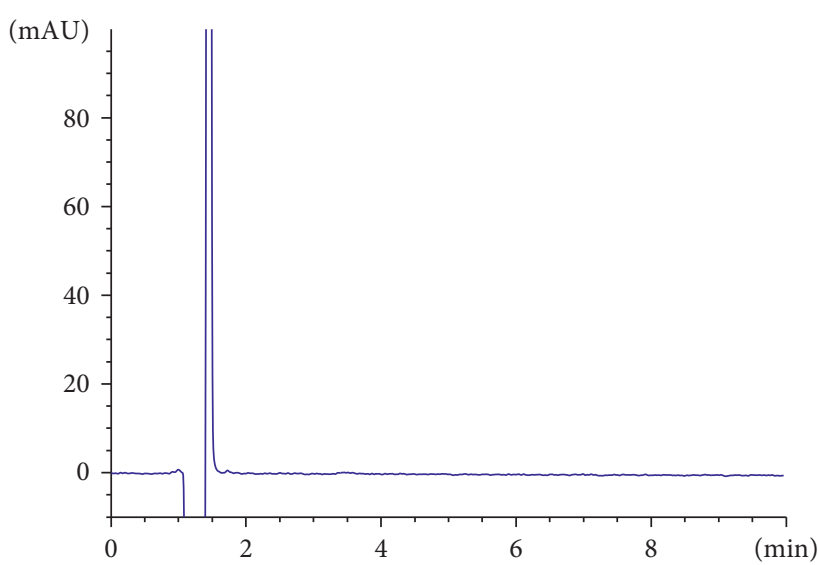

(c)

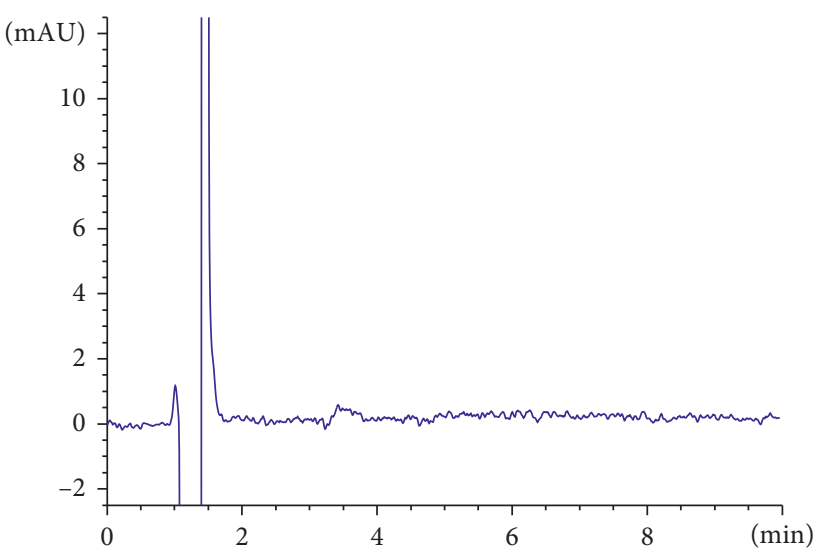

(e)

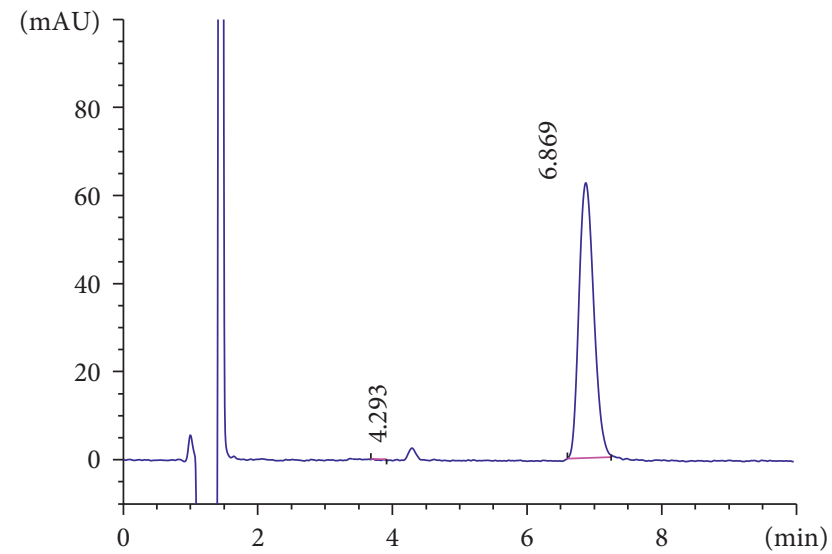

(b)

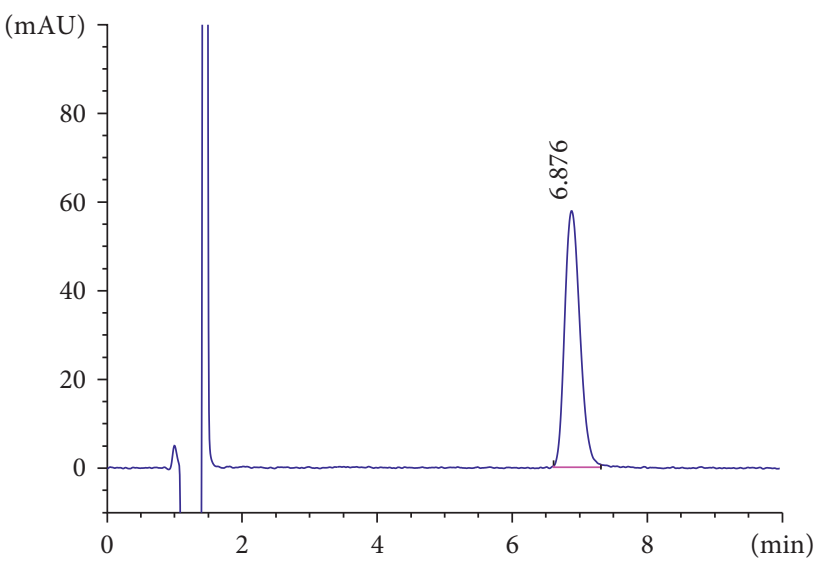

(d)

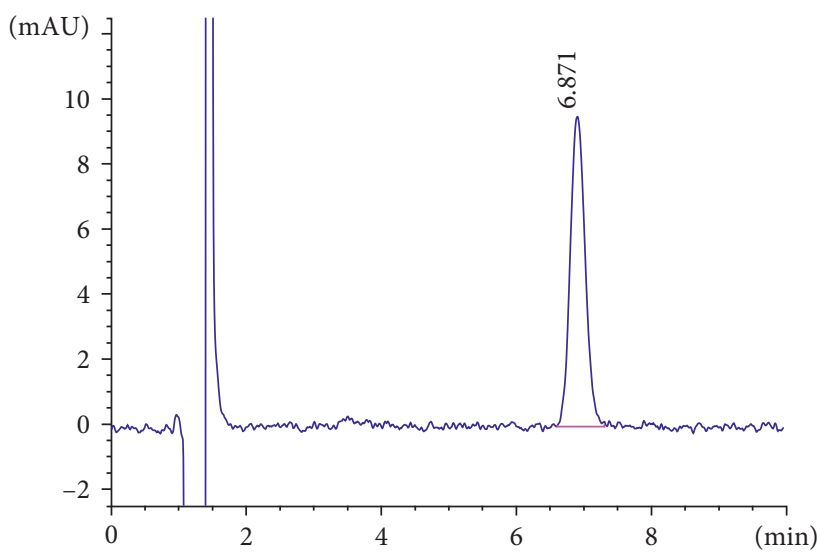

(f)

FIGURE 3: HPLC chromatograms illustrating absence of any matrix interfering peak around the RHT retention time (6.9 minutes). Chromatograms of (a) empty dual-ligand NPs matrix, (b) RHT-loaded dual-ligand NPs matrix, (c) release medium after 24-hour release study of empty dual-ligand NPs, (d) release medium after 24-hour release study of RHT-loaded dual-ligand NPs, (e) cell transport medium, and (f) released RHT from NPs in cell transport medium after the transport study.

components such as excipients, reactions components, release medium, and cellular transport medium. The accuracy of the proposed method was calculated as percentage recovery from the six concentrations covering the entire RHT concentration range within the calibration curve. RHT was successfully recovered from all samples in three experimental media (Table 5) with an accuracy of $99.5 \pm 1 \%$, which is within the acceptable range [40]. This suggests that none of the matrices in the dual-ligand nanoparticle formulation or medium/buffer is interfering 
TABLE 3: The precision of the HPLC method for determination of RHT.

\begin{tabular}{|c|c|c|c|c|c|c|}
\hline \multirow{2}{*}{$\begin{array}{l}\text { RHT conc. } \\
(\mu \mathrm{g} / \mathrm{mL})\end{array}$} & \multicolumn{2}{|l|}{ RHT in NPs matrix } & \multicolumn{2}{|c|}{ RHT in release medium } & \multicolumn{2}{|c|}{ RHT in cell transport medium } \\
\hline & $\begin{array}{c}\text { Average RHT peak area } \\
(\mathrm{mAU} \times \mathrm{sec})\end{array}$ & $\begin{array}{l}\text { RSD } \\
(\%)\end{array}$ & $\begin{array}{c}\text { Average RHT peak area } \\
(\mathrm{mAU} \times \mathrm{sec})\end{array}$ & $\begin{array}{l}\text { RSD } \\
(\%)\end{array}$ & $\begin{array}{l}\text { Average RHT peak area } \\
(\mathrm{mAU} \times \mathrm{sec})\end{array}$ & $\begin{array}{l}\text { RSD } \\
(\%)\end{array}$ \\
\hline 1 & 36.50 & 1.04 & 36.22 & 1.28 & 36.02 & 1.06 \\
\hline 4 & 145.97 & 0.59 & 145.82 & 0.67 & 144.24 & 0.66 \\
\hline 6 & 219.73 & 0.49 & 220.98 & 0.28 & 218.64 & 0.48 \\
\hline 10 & 370.20 & 0.17 & 369.30 & 0.19 & 369.15 & 0.23 \\
\hline
\end{tabular}

TABLE 4: Intra- and interday repeatability of RHT analysis in NPs matrix, release medium, and cell transport medium.

\begin{tabular}{|c|c|c|c|c|c|c|}
\hline \multirow{2}{*}{$\begin{array}{l}\text { RHT concentration } \\
(\mu \mathrm{g} / \mathrm{mL})\end{array}$} & \multicolumn{2}{|c|}{$\begin{array}{c}\text { RHT in NPs matrix (200x diluted } \\
\text { in mobile phase) }\end{array}$} & \multicolumn{2}{|c|}{ RHT in release medium } & \multicolumn{2}{|c|}{ RHT in cell transport medium } \\
\hline & Intraday $\mathrm{RSD}^{\mathrm{b}}$ & Interday $\mathrm{RSD}^{\mathrm{c}}$ & Intraday $\mathrm{RSD}^{\mathrm{b}}$ & Interday $\mathrm{RSD}^{\mathrm{c}}$ & Intraday $\mathrm{RSD}^{\mathrm{b}}$ & Interday $\mathrm{RSD}^{\mathrm{c}}$ \\
\hline 1 & 0.69 & 1.32 & 0.73 & 0.64 & 0.94 & 1.24 \\
\hline 5 & 0.92 & 0.92 & 0.65 & 1.11 & 0.51 & 1.11 \\
\hline 10 & 0.49 & 1.19 & 0.35 & 1.02 & 0.15 & 0.95 \\
\hline
\end{tabular}

${ }^{\mathrm{a}}$ Each concentration was analysed in triplicate $(n=3)$; ${ }^{\mathrm{b}}$ the analyses were carried out at 0,3 , and $8 \mathrm{hrs}$ on the same day, and all data were included in the calculation; ${ }^{c}$ the analyses were carried out at days 1 and 2 , and all data were included in the calculation.

TABle 5: Accuracy data for RHT in NPs matrix, release medium, and cell transport medium.

\begin{tabular}{|c|c|c|c|c|c|c|}
\hline \multirow{2}{*}{$\begin{array}{l}\text { Prepared RHT } \\
\text { concentration }(\mu \mathrm{g} / \mathrm{mL})\end{array}$} & \multicolumn{2}{|c|}{ RHT in NPs matrix } & \multicolumn{2}{|c|}{ RHT in release medium } & \multicolumn{2}{|c|}{ RHT in cell transport medium } \\
\hline & $\begin{array}{c}\text { Measured } \\
\text { concentration }(\mu \mathrm{g} / \mathrm{mL})\end{array}$ & $\begin{array}{c}\text { Recovery } \\
(\%)\end{array}$ & $\begin{array}{c}\text { Measured } \\
\text { concentration }(\mu \mathrm{g} / \mathrm{mL})\end{array}$ & $\begin{array}{c}\text { Recovery } \\
(\%)\end{array}$ & $\begin{array}{c}\text { Measured } \\
\text { concentration }(\mu \mathrm{g} / \mathrm{mL})\end{array}$ & $\begin{array}{c}\text { Recovery } \\
(\%)\end{array}$ \\
\hline 0.50 & $0.49 \pm 0.13$ & $98.0 \pm 0.2$ & $0.49 \pm 0.11$ & $98.4 \pm 0.1$ & $0.49 \pm 0.16$ & $98.6 \pm 0.2$ \\
\hline 2.00 & $1.99 \pm 0.16$ & $99.5 \pm 0.3$ & $2.01 \pm 0.10$ & $\begin{array}{c}100.5 \pm \\
0.3\end{array}$ & $2.00 \pm 0.12$ & $99.8 \pm 0.2$ \\
\hline 4.00 & $3.96 \pm 0.19$ & $99.0 \pm 0.3$ & $4.04 \pm 0.24$ & $\begin{array}{c}101.0 \pm \\
0.2\end{array}$ & $3.95 \pm 0.31$ & $98.7 \pm 0.3$ \\
\hline 6.00 & $5.97 \pm 0.11$ & $99.5 \pm 0.1$ & $5.95 \pm 0.25$ & $99.2 \pm 0.2$ & $5.93 \pm 0.15$ & $98.8 \pm 0.2$ \\
\hline 8.00 & $8.03 \pm 0.16$ & $\begin{array}{c}100.4 \pm \\
0.3\end{array}$ & $7.98 \pm 0.19$ & $99.8 \pm 0.6$ & $7.97 \pm 0.16$ & $99.6 \pm 0.2$ \\
\hline \multirow[t]{2}{*}{10.00} & $9.99 \pm 0.37$ & $99.9 \pm 0.2$ & $9.99 \pm 0.15$ & $99.9 \pm 0.2$ & $9.98 \pm 0.24$ & $99.8 \pm 0.1$ \\
\hline & \multicolumn{2}{|c|}{ Mean $\pm \mathrm{SD}=99.4 \pm 0.8$} & \multicolumn{2}{|c|}{ Mean $\pm \mathrm{SD}=99.8 \pm 0.9$} & \multicolumn{2}{|c|}{ Mean $\pm S D=99.2 \pm 0.9$} \\
\hline
\end{tabular}

with the assay of RHT. It can be concluded that the developed HPLC assay method can be used to produce accurate data.

\section{Conclusion}

To assist the development of dual-ligand NP formulations for brain drug delivery, we have developed a simple, fast, accurate, and reliable HPLC method for RHT analysis during the formulation development and evaluation. This HPLC method has been validated for analysis of RHT loading in dual-ligand NPs preparations, in vitro drug release, and cellular transport studies. The chromatographic separation was achieved using a $\mathrm{C}_{18}$ column maintained at $50^{\circ} \mathrm{C}$ and an isocratic mobile phase consisting of TFA containing ACN and water with a flow rate of $1.5 \mathrm{~mL} / \mathrm{min}$. The method exhibited good linearity over the assayed concentration range and good intra- and interday precision. The developed HPLC method is accurate, selective, and rugged for RHT analysis with good detection and quantification limits and is suitable for its intended use. This stability indicating analytical method can be adapted easily to analyse RHT in pharmaceutical formulations and biological matrices and for the future use in HPLC-MS analysis.

\section{Conflicts of Interest}

The authors declare that there are no conflicts of interest regarding the publication of this article.

\section{Acknowledgments}

The authors wish to thank Dr. Andrew Crowe, Mr. Giuseppe Luna, Mr. Michael Boddy, Ms. Yan-Jing Ng, and Ms. Yeakuty Marzan Jhanker for their technical assistance. Naz Hasan Huda and Bhawna Gauri wish to acknowledge the support of Curtin Strategic International Research Scholarship (CSIRS). 


\section{References}

[1] J. Cherian and K. Gohil, "Cautious optimism for growth in Alzheimer's disease treatments," Pharmacy and Therapeutics, vol. 40, no. 4, pp. 288-289, 2015.

[2] N. H. Greig, T. Utsuki, D. K. Ingram et al., "Selective butyrylcholinesterase inhibition elevates brain acetylcholine, augments learning and lowers Alzheimer $\beta$-amyloid peptide in rodent," Proceedings of the National Academy of Sciences of the United States of America, vol. 102, no. 47, pp. 17213-17218, 2005.

[3] G. T. Grossberg, "Cholinesterase inhibitors for the treatment of Alzheimer's disease: getting on and staying on," Current Therapeutic Research, Clinical and Experimental, vol. 64, no. 4, pp. 216-235, 2003.

[4] M. Pohanka, "Inhibitors of acetylcholinesterase and butyrylcholinesterase meet immunity," International Journal of Molecular Sciences, vol. 15, no. 6, pp. 9809-9825, 2014.

[5] A. Kumar, A. Singh, and Ekavali, "A review on Alzheimer's disease pathophysiology and its management: an update," Pharmacological Reports, vol. 67, no. 2, pp. 195-203, 2015.

[6] F. Zemek, L. Drtinova, E. Nepovimova et al., "Outcomes of Alzheimer's disease therapy with acetylcholinesterase inhibitors and memantine," Expert Opinion on Drug Safety, vol. 13, no. 6, pp. 759-774, 2014.

[7] M. R. Farlow, G. T. Grossberg, C. H. Sadowsky, X. Meng, and D. M. Velting, "A 24-week, open-label extension study to investigate the long-term safety, tolerability, and efficacy of $13.3 \mathrm{mg} / 24 \mathrm{~h}$ rivastigmine patch in patients with severe Alzheimer disease," Alzheimer Disease \& Associated Disorders, vol. 29, no. 2, pp. 110-116, 2015.

[8] J. S. Birks, L. Y. Chong, and J. Grimley Evans, "Rivastigmine for Alzheimer's disease," Cochrane Database of Systematic Reviews, no. 9, pp. 1-198, 2015.

[9] B. Wilson, M. K. Samanta, K. Santhi, K. P. S. Kumar, N. Paramakrishnan, and B. Suresh, "Poly(n-butyl cyanoacrylate) nanoparticles coated with polysorbate 80 for the targeted delivery of rivastigmine into the brain to treat Alzheimer's disease," Brain Research, vol. 1200, pp. 159-168, 2008.

[10] N. H. Huda, "Development of a novel nanoparticulate carrier system for enhancement of bioactive molecule delivery into the brain," Ph.D. thesis, School of Pharmacy, Curtin University, Perth, Australia, 2017.

[11] B. Gauri, "Development and evaluation of an intranasal nanoparticulate formulation for enhanced transport of rivastigmine into the brain," Ph.D. thesis, School of Pharmacy, Curtin University, Perth, Australia, 2017.

[12] M. Fazil, S. Md, S. Haque et al., "Development and evaluation of rivastigmine loaded chitosan nanoparticles for brain targeting," European Journal of Pharmaceutical Sciences, vol. 47, no. 1, pp. 6-15, 2012.

[13] K. Nagpal, S. K. Singh, and D. N. Mishra, "Optimization of brain targeted chitosan nanoparticles of rivastigmine for improved efficacy and safety," International Journal of Biological Macromolecules, vol. 59, pp. 72-83, 2013.

[14] B. Shah, D. Khunt, H. Bhatt, M. Misra, and H. Padh, "Application of quality by design approach for intranasal delivery of rivastigmine loaded solid lipid nanoparticles: effect on formulation and characterization parameters," European Journal of Pharmaceutical Sciences, vol. 78, pp. 54-66, 2015.

[15] Z.-Z. Yang, Y.-Q. Zhang, Z.-Z. Wang, K. Wu, J.-N. Lou, and X.-R. Qi, "Enhanced brain distribution and pharmacodynamics of rivastigmine by liposomes following intranasal administration," International Journal of Pharmaceutics, vol. 452, no. 12, pp. 344-354, 2013.

[16] R. Mullangi, A. Ranjithkumar, K. Arumugam et al., "High performance liquid chromatographic fluorescence detection method for the quantification of rivastigmine in rat plasma and brain: application to preclinical pharmacokinetic studies in rats," Journal of Young Pharmacists, vol. 3, no. 4, pp. 315-321, 2011.

[17] K. Arumugam, G. Subramanian, S. Mallayasamy, R. Averineni, M. Reddy, and N. Udupa, "A study of rivastigmine liposomes for delivery into the brain through intranasal route," Acta Pharmaceutica, vol. 58, no. 3, pp. 287-297, 2008.

[18] L. Lee, M. Hossain, Y. Wang, and G. Sedek, "Absorption of rivastigmine from different regions of the gastrointestinal tract in humans," Journal of Clinical Pharmacology, vol. 44, no. 6, pp. 599-604, 2004.

[19] M. Hossain, S. S. Jhee, T. Shiovitz et al., "Estimation of the absolute bioavailability of rivastigmine in patients with mild to moderate dementia of the Alzheimer's type," Clinical Pharmacokinetics, vol. 41, no. 3, pp. 225-234, 2002.

[20] Y. Sha, C. Deng, Z. Liu, T. Huang, B. Yang, and G. Duan, "Headspace solid-phase microextraction and capillary gas chromatographic-mass spectrometric determination of rivastigmine in canine plasma samples," Journal of Chromatography $B$, vol. 806, no. 2, pp. 271-276, 2004.

[21] K. Arumugam, M. R. Chamallamudi, R. R. Gilibili et al., "Development and validation of a HPLC method for quantification of rivastigmine in rat urine and identification of a novel metabolite in urine by LC-MS/MS," Biomedical Chromatography, vol. 25, no. 3, pp. 353-361, 2011.

[22] F. Pommier and R. Frigola, "Quantitative determination of rivastigmine and its major metabolite in human plasma by liquid chromatography with atmospheric pressure chemical ionization tandem mass spectrometry," Journal of Chromatography B, vol. 784, no. 2, pp. 301-313, 2003.

[23] J. Bhatt, G. Subbaiah, S. Kambli et al., "A rapid and sensitive liquid chromatography-tandem mass spectrometry (LCMS/MS) method for the estimation of rivastigmine in human plasma," Journal of Chromatography B, vol. 852, no. 1-2, pp. 115-121, 2007.

[24] S. V. Frankfort, M. Ouwehand, M. J. van Maanen, H. Rosing, L. R. Tulner, and J. H. Beijnen, "A simple and sensitive assay for the quantitative analysis of rivastigmine and its metabolite NAP 226-90 in human EDTA plasma using coupled liquid chromatography and tandem mass spectrometry," Rapid Communications in Mass Spectrometry, vol. 20, no. 22, pp. 3330-3336, 2006.

[25] A. Enz, A. Chappuis, and A. Dattler, "A simple, rapid and sensitive method for simultaneous determination of rivastigmine and its major metabolite NAP 226-90 in rat brain and plasma by reversed-phase liquid chromatography coupled to electrospray ionization mass spectrometry," Biomedical Chromatography, vol. 18, no. 3, pp. 160-166, 2004.

[26] H. Amini and A. Ahmadiani, "High-performance liquid chromatographic determination of rivastigmine in human plasma for application in pharmacokinetic studies," Iranian Journal of Pharmaceutical Research, vol. 9, no. 2, pp. 115-121, 2010.

[27] B. M. Rao, M. K. Srinivasu, K. Praveen Kumar et al., "A stability indicating LC method for rivastigmine hydrogen tartrate," Journal of Pharmaceutical and Biomedical Analysis, vol. 37, no. 1, pp. 57-63, 2005. 
[28] A. Karthik, G. Subramanian, M. Surulivelrajan, A. Ranjithkumar, and S. Kamat, "Fluorimetric determination of rivastigmine in rat plasma by a reverse phase-high performance liquid chromatographic method. Application to a pharmacokinetic study," Arzneimittelforschung, vol. 58, no. 5, pp. 205-210, 2008.

[29] C. P. Li, L. Zheng, M. Mao, G. Rao, and W. Shan, "HPLC determination of rivastigmine hydrogen tartrate capsules," Chinese Journal of Pharmaceutical Analysis, vol. 31, no. 6, pp. 1123-1125, 2011.

[30] S. P. Sulochana, K. Sharma, R. Mullangi, and S. K. Sukumaran, "Review of the validated HPLC and LC-MS/MS methods for determination of drugs used in clinical practice for Alzheimer's disease," Biomedical Chromatography, vol. 28, no. 11, pp. 1431-1490, 2014.

[31] M. J. Ramalho and M. C. Pereira, "Preparation and characterization of polymeric nanoparticles: an interdisciplinary experiment," Journal of Chemical Education, vol. 93, no. 8, pp. 1446-1451, 2016.

[32] F. T. Meng, G. H. Ma, Y. D. Liu, W. Qiu, and Z. G. Su, "Microencapsulation of bovine hemoglobin with high bioactivity and high entrapment efficiency using a W/O/W double emulsion technique," Colloids and Surfaces B: Biointerfaces, vol. 33, no. 3-4, pp. 177-183, 2004.

[33] M. Ben David-Naim, E. Grad, G. Aizik et al., "Polymeric nanoparticles of siRNA prepared by a double-emulsion solvent-diffusion technique: physicochemical properties, toxicity, biodistribution and efficacy in a mammary carcinoma mice model," Biomaterials, vol. 145, pp. 154-167, 2017.

[34] T. S. Raju, L. Kalyanaraman, V. Venkat Reddy, and P. Yadagiri Swamy, "Development and validation of an UPLC method for the rapid separation of positional isomers and potential impurities of rivastigmine hydrogen tartrate in drug substance and drug product," Journal of Liquid Chromatography \& Related Technologies, vol. 35, no. 7, pp. 896-911, 2012.

[35] P. P. Dandekar and V. B. Patravale, "Development and validation of a stability-indicating LC method for curcumin," Chromatographia, vol. 69, no. 9-10, pp. 871-877, 2009.

[36] ICH, "Stability testing of new drug substances and products (Q1AR)," 2000

[37] ICH, "Q2B validation of analytical procedures: methodology," 1996.

[38] USP-NF, "Validation of compendial procedures," in The United States Pharmacopeia 37/National Formulary 32, 2014, The United States Pharmacopeia Convention, Inc., Rockville, MD, USA, 2006.

[39] D. J. Canney, "Cholinomimetic drugs," in Remington: The Science and Practice of Pharmacy, R. Hendrickson, Ed., p. 1397, Wolters Kluwer Health/Lippincott, Williams \& Wilkins, Baltimore, MD, USA, 2005.

[40] M. E. Swartz and I. S. Krull, "Method validation basics," in Handbook of Analytical Validation, pp. 61-80, CRC Press, Boca Raton, FL, USA, 2012. 

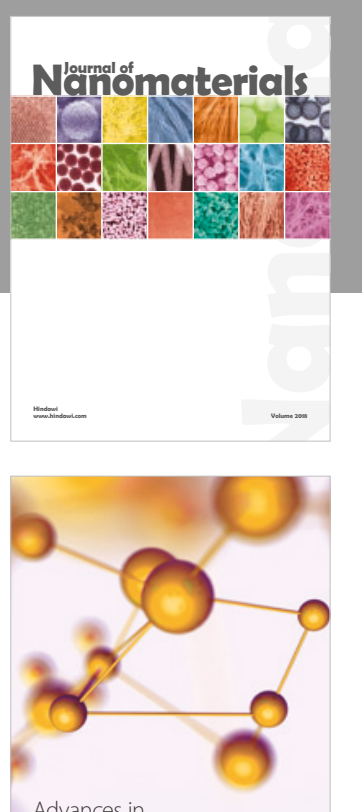

Physical Chemistry
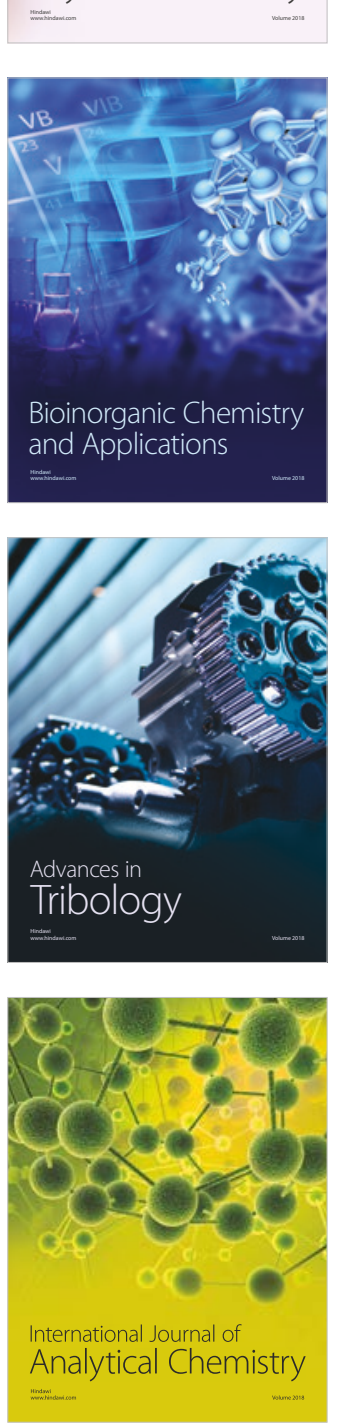

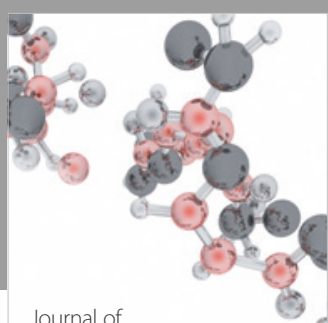

Analytical Methods

in Chemistry

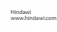

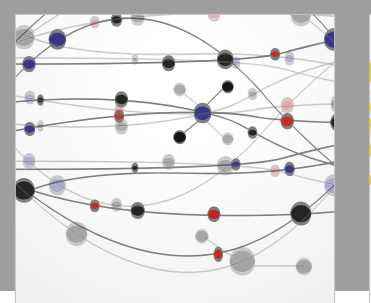

The Scientific World Journal

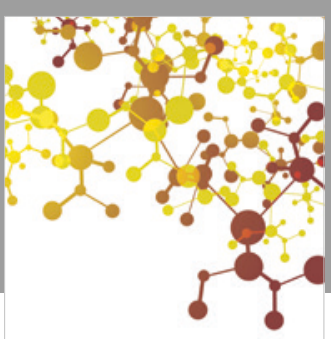

Journal of

Applied Chemistry
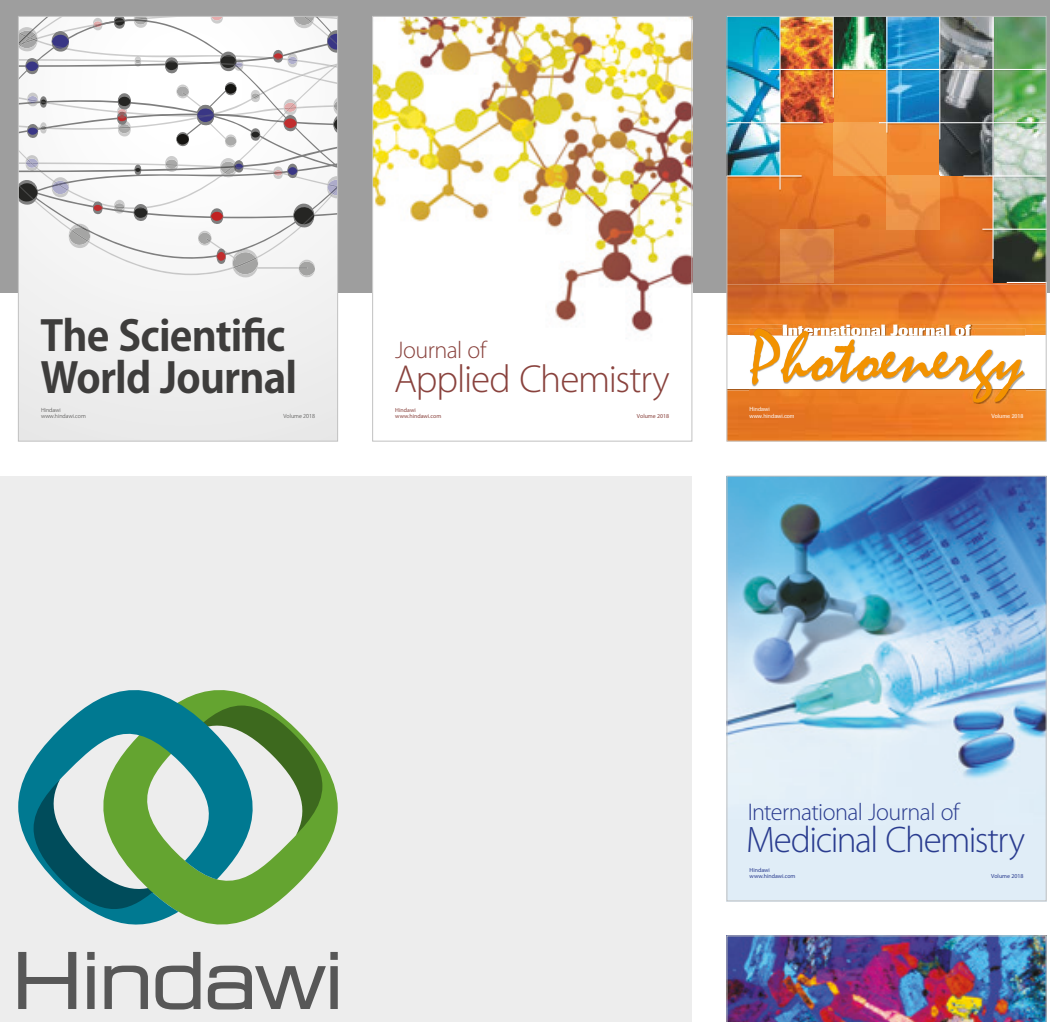

Submit your manuscripts at

www.hindawi.com
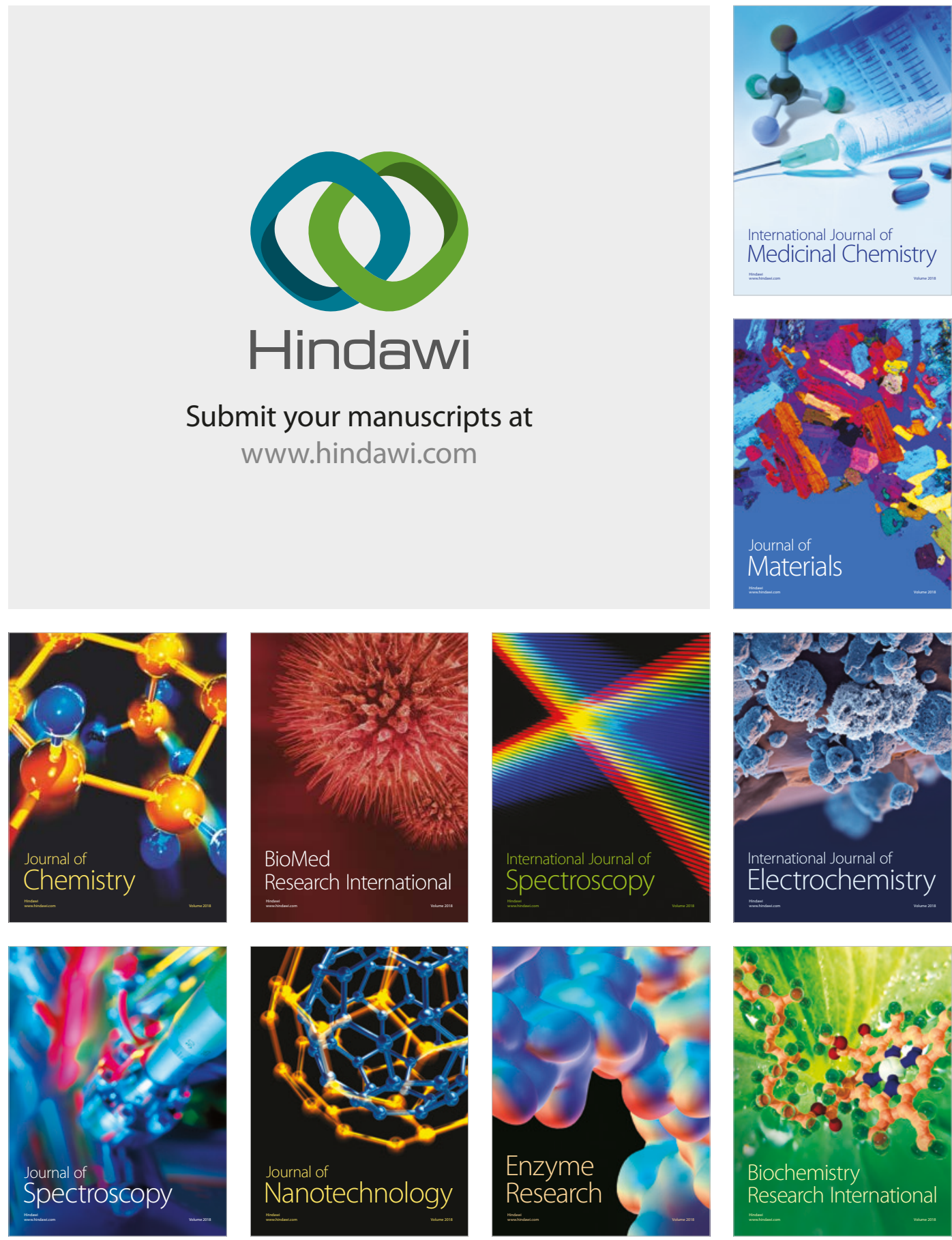
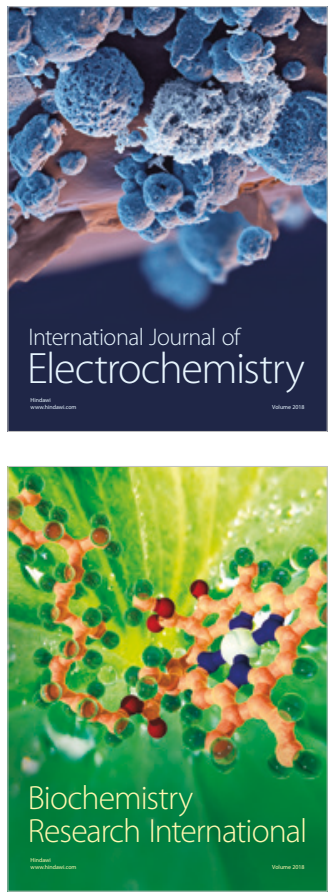